\title{
Composite Resins - Multifunctional Restorative Material and Practical Approaches in Dental Field
}

\author{
ALICE MURARIU1, CIPRIAN DINU ${ }^{2}$, DORIANA AGOP FORNA ${ }^{1}$, \\ VICTORITA STEFANESCU ${ }^{2 *}$, GABI TOPOR ${ }^{2}$, NORINA CONSUELA FORNA ${ }^{1}$, \\ SILVIA FOTEA ${ }^{2}$, GABRIELA GURAU ${ }^{2}$, CRISTINA IORDACHE ${ }^{1}$ \\ ${ }^{1}$ Grigore T. Popa University of Medicine and Pharmacy, Faculty of Dental Medicine, 16 University Str., 700115, Iasi, \\ Romania \\ ${ }^{2}$ Dunarea de Jos University, Medicine \& Pharmacy Faculty, Dentistry Dept., 47 Domneasca Str., Galati, 800008, Romania
}

\begin{abstract}
With a wide range of composite resins available today, clinicians can benefit from knowledge of the infrastructure of a particular material in order to determine which type will work best in a specific clinical situation. The purpose of this study is to analyze the biomechanical behavior of four types of composite resins, two of them used in direct restorations and the other two for prosthetic restorations created in the lab.The deformations, hardness and elasticity were analyzed under the same conditions, namely at $200 \mathrm{Mpa}$, as these are very important parameters for the biomechanical behavior of the analyzed biomaterials, the specificity elements being correlated with the biomaterial structure, polymerization time and polymerization modality. As a synthesis of the biomechanical behavior outcome related to the used resins versus the resins used in the lab of dental technique using indirect means, a relatively wide range of higher value parameters stands out with regard to resistance for the lab composites compared to those used in direct restorations.
\end{abstract}

Keywords: aesthetic restoration, prosthetic works, composite resins.

\section{Introduction}

In daily practice, composite resins offer special benefits. They allow clinicians to follow a predictable, conservative and safe chair protocol to improve patients' smiles and restore worn or decayed dental structures. Combined with the best adhesive protocols, these procedures can be used successfully to achieve beautiful results [1-3]. Composite laboratory resins respond very well as a restorative multifunctional material without a limitation in terms of aesthetics without strain on the from the financial point of view. This materials are available to clinicians and do not require much effort on the part of either the technician or the dentist. Thus, photopolymerizable composite resins can be a very good indication where the technical conditions of the clinic or the material condition of the patient exclude the use of porcelain. The evolution in time of composite resins is the following:

In 1871, Thomas Fletcher introduced a new material for fillings, called cement silicate. Its use in dentistry continued for a long time, although the aesthetics obtained were not ideal. It represented the elective material until the development of composite resins. Composite resin technology was first introduced in 1958 with the development of a high molecular weight monomer called bisphenol Aglycidyl methacrylate or Bis-GMA. Along with the development of acid etching in 1955, these two discoveries represented the breakthrough for the composite resin technologies currently in use[4-6].

The first composite resins were composed of a base and a catalyst and were chemically polymerized. This made the procedure somewhat difficult, but their use was still simpler than in the case of silicate cements, and the aesthetics were superior. With the introduction of light-curable composite resins in the 1970s, dentistry became more predictable, proving longer working time and better physical properties. These composite resins were more stable in color and contained smaller particles than their predecessor self-curing resins [7-9].

\footnotetext{
*email: victorita.stefanescu@ugal.ro
} 
In the late 1970s, microfill resins with medium submicron particle size were introduced, which led to increase polishability and wear. The following decade saw a decrease in particle size and an increase in filler load, which significantly improved light-curable composite resins for universal use in the front and side regions. Today, after 50 years of material science and laboratory development, as well as clinical trials in human subjects, composite resins have been revalidated as a universal restorative material. Numerous various composite resin systems are currently available. To determine which material will work best in a given clinical situation, clinicians need to know the composite resin infrastructure, which contains three phases: the organic phase (matrix); dispersed phase (filling); and the interface phase (coupling agent). In essence, composite resins consist of a continuous polymeric or resin matrix, in which the inorganic filler is dispersed. The addition of fillers to dental composite resins significantly strengthens their physical properties by increasing the strength and strengthening the matrix, reducing the coefficient of termic expansion. There are many fillers for composite resins. These materials include quartz, alumina, zinc, zirconium, to name a few. Fillers may vary in size, depending on the manufacturing process [10-12].

Many manufacturers are trying to increase the amount of filler in resins, in order to improve such mechanical and physical properties, such as would be the resistance to compression and to bending, modulus of elasticity, coefficient of termo expansion, the absorption of water and resistance to wear. They were developed in more systems of classification on the basis of size particles, the distribution and the amount incorporated. The classifications are more commonly referred to as a hybrid, microhybrid, composites with micro filler and the newest with nano - filler. The disclosures of these classifications may vary from one system to the other. The hybrid and microhybrid materials have, in general, a content of the filler of about $75 \%$ by weight. The particles of the filler may vary in size from 1-3 microns, and include particles of dioxide of silicon, which have usually a size of 0.04 microns. Hybrid materials show strength superior to the tensile, shrinkage reduced of the polymerization the coefficient decreased by expansion heat, resistance improved in abrasion and a more good resistance to fracturing. The disadvantage of hybrid materials is their weak polishability and the need for maintenance of gloss over time. In order to have a strong adhesion between the matrix and the filler, a coupling agent is used. The modification of the filler component remains the most significant development in the evolution of composite resins. The use of the photopolymerizable composite resins was first felt in the in dental surgeries. Here this kind of materials together with the lamps them light spectrum have deeply changed operative dentistry. Before them there were no initial restorations that used the heat as an item of polymerization of the acrylic resin and for the crowns that were to be fixed into their seats. With low elasticity and relative dimensional instability, they caused fractures in the cement under the action of caries, cracks or restoration edges[13$15]$.

In 1940, acrylic autopolimerizable (type I) could be placed towards the prepared cavity of the tooth. The polymer and monomer were combined and inserted into the prepared cavity of the tooth where they polymerized. The difficulties that arose when using this material were: color instability; the fact that they get darker when exposedto light (these difficulties made the material not be used in longterm recovery); very short working period for processing (1.5 minutes); poor compressive strength $(10,000$ psi); low abrasion resistance; low elasticity coefficient $(2.4 \mathrm{GPa})$; increased level of water absorption; polymerization expansion of $7 \%$ of the volume; increased coefficient of thermal expansion. Last deficiency, which is actually the most important, it is that it can create problems in marginal adapting. The second type of resin was made by Bown in the early 60s. His studies inserted into the resin contents an organic compound related to a proportion of inorganic filler as an agent to adhere to the resine matrix - a mixture between bisphenol and glycidylmetacrilat (BISGMA). In the early 1970s, the use of ultraviolet light began to activate a photosensitive element. This element was replaced by a component that reacts to light in the visible spectrum $(\chi=400 \mathrm{~nm})$. The initial chemical resins and those in the light spectrum is also be used in the current way. The 
photopolymerization system has the following advantages: can be controlled throughout preparation; the finishing of the restoration can be taken away; the control throughout polymerized is assured.

However, the autopolymerizable resins have also the advantage that they can be placed in the oral cavity inaccessible to light [16-18].

From the point of view of mechanical and physical qualities the composite resins are superior by: resistance to compression; low coefficient of thermal expansion, low water absorption; increased surface hardness[19-21].

Today, research provides the clinician with three major categories of composite resins: microfilled, macrofilled, hybrid. Composite microfilm resins appeared in 1980 from the need of a material with a high degree of finisability, color stability and a clinic durability. The filler particles (load) have a diameter of $0.4 \mu \mathrm{m}$, a load that represents approximately $35-50 \%$ of the weight of the composite resin, in contrast to macrofilled which have $70-80 \%$ filler. It is used more when the prevailing aesthetics such as the restoration of cavities of classes III, IV and rebuilding the lower cavity and cavities class $\mathrm{V}$ and prosthetic for vestibular veneers or situations in which the polishing surface is desired[22-24].

The composite resins macro type describes a type of composite resins with inorganic filler consisting of particles of sizes larger than $1-5 \mu \mathrm{m}$ in diameter, which is $70-80 \%$ of the weight of the material. Due to the large particle size this material cannot be polished in the same way as microfilled. The advantage is a significant increase in hardness and wear resistance. It has indicated and the user cavities of class I, II, IV and for the restoration of the incisal edge of jaw incisors. Lately, there are used rarely, due to the poor aesthetic qualities. Hybrid type composite resins appeared to meet the need to combine both qualities (gloss and strength).

Thus, many factories started to produce a hybrid with a quantity increased to $70-80 \%$ with both types of microparticles $(0.4 \mu)$ and macroparticles $(1-3 \mu \mathrm{m})$. The indication for use is the same as for macrofille. Today, many manufacturers are trying to increase the amount of filling resin for them, to thus improve mechanical properties and physical properties, such as compressive strength and flexural strength, elastic modulus, thermal expansion coefficient, water absorption and resistance to wear[2527].

Microstructure is in particles of dioxide of silicon submicroscopic having dimensions of approxima tely $0.04 \mu \mathrm{m}$. Taking into account the difficulty wetting these particles lower, the concentration of the filler is usually, $35 \%$ from weight. The amount of more reduced particles allows a great polishability, and the ability to maintain the gloss in time. These types of materials are significantly weaker than hybrids and show a higher absorption of water, the lack of radioopacity and less resistance reduced to fracture. They are better used in combination with a hybrid material on the oral surface, for a better resistance in the areas with low stress, too.

They are very suitable for restorations of class 3rd and 5th, and also for facets, directly[28-30].

\section{Material and methods}

The purpose of this study is to analyze the biomechanical behavior of four types of composite resins, two of them used in direct restorations and the other two for prosthetic restorations created in the lab.

The deformations, hardness and elasticity were analyzed under the same conditions, namely at 200 $\mathrm{Mpa}$, as these are very important parameters for the biomechanical behavior of the analyzed biomaterials, the specificity elements being correlated with the biomaterial structure, polymerization time and polymerization modality.

In the category of composites used for direct crown restoration, the materials under analysis were represented by Gradia anterior(GC), a hybrid composite material designed for esthetic restorations, prevalent in the anterior area and by Gradia posterior(GC), a hybrid resin composite with micro-filling for posterior crown restorations.

From the category of lab composites we selected Gradia Plus(GC), a photopolymerizable microceramic composite, whose internal structure consists in improved bonds between the organic-inorganic 
filling and the resin matrix and the Solidex composite(Shofu), a micro-hybrid photo composite with a filling of over 53\% of ceramic particles. 4 test samples were created using the analyzed materials, with the same dimensions $(250 \times 25 \times 5 \mathrm{~mm})$, being subject to traction forces on the universal testing machine (Textenser).

Polymerization of cabinet composites (Gradia anterior, Gradia posterior) was made with a Woodpecker LED.B Photopolymerization lamp, Voltage: 110-240V, AC, 50-60Hz, wavelength: 420$480 \mathrm{~nm}$ and luminous power: 1000-max $1200 \mathrm{~mW} / \mathrm{cm} 2$ and the working time was 20s. The polymerization of laboratory composites was achieved at $90 \mathrm{~s}$ with the means of the polymerization oven(Laborlux 3), with following characteristics 310-500nm, 300W .

The operation regime of the Textenser universal trial machine for variable forces was determined through the 27 (FATIGUE) switch in ON position (when it is in OFF position, the machine only executes trials at unique traction). Lamp 28, located under switch 27 , is lit when the switch is moved to ON.

The cycle counter 29 needs to be set so that the indication of the cycle limit number (30.a) exceeds the indication of the performed cycles number (30.b), which is usually brought to zero by pressing the black button near the lower window (performed cycle counter). During the trials, in the lower counter the number of performed cycles is summed up and the upper counter shows the number of cycles to be performed. The strain limits (movement of the mobile beam) were chosen with an accuracy of $0.1 \mathrm{~mm}$ with the device 24, (marked with STRAIN LIMIT): low value $(L O W)$ and high value $(H I G H)$ were chosen by rotating the selectors. As a synthesis of the biomechanical behavior outcome related to the used resins versus the resins used in the lab of dental technique using indirect means, a relatively wide range of higher value parameters stands out with regard to resistance for the lab composites compared to those used in direct restorations.

\section{Results and discussions}

Table 1. Physical properties of composite resins for the clinic compared to laboratory ones

\begin{tabular}{|c|c|c|}
\hline & LABORATORY & CLINICAL \\
\hline $\begin{array}{c}\text { Voltage resistance(N/ } \\
\mathrm{mm}^{2)}\end{array}$ & $80-120$ & $70-80$ \\
\hline Deformation at 200MPa & $3.5-4.5$ & $8-9$ \\
\hline Hardness N/ $\mathrm{mm}^{2}$ & $500-600$ & $360-410$ \\
\hline Elastic modulus N/ $\mathrm{mm}^{2}$ & $7000-10000$ & $4000-5500$ \\
\hline
\end{tabular}

Regarding the stress resistance, the superiority of Gradia Plus lab composite stands out, followed by Solidex, with a much lower stress resistance for the composites used in the direct restorations, a better resistance being displayed by the Gradia composite for the posterior area and the Gradia composite for the anterior area. A deformation risk was recorded for the composites used for direct restorations, a higher risk in case of Gradia composite used for esthetic restorations, followed by gradia posterior, whose higher hardness recommends it in the areas of greater masticatory forces (Figure 1, Figure 2) 

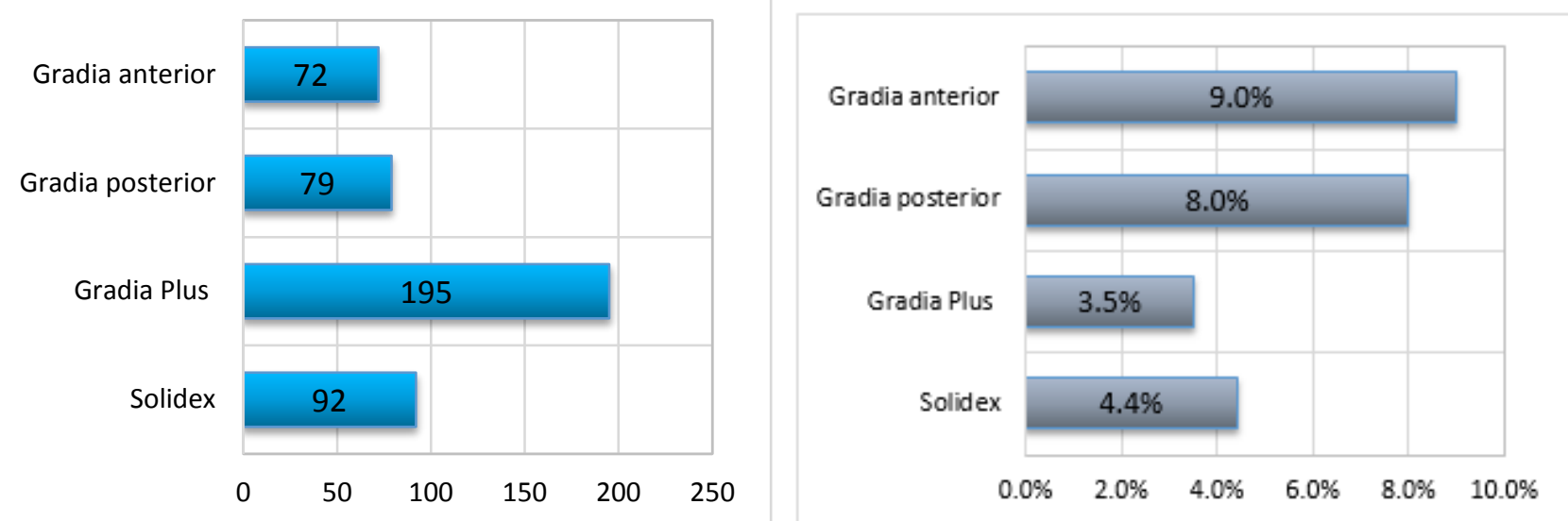

Figure 1, 2. Aspect of resistence risk and stress resistence at analysed materials

Very good deformation resistance was obtained for lab composites, the first place being taken by Gradia Plus, which through the chemical bonds established between the organic-inorganic filling and the resin matrix reached a hardness of 9.9350, the following position in terms of hardness being taken by Solidex, and for the lab composites higher values were recorded, 598 for Gradia plus and 512 for Solidex, while for the direct restoration composites, the elasticity module reached was 398 for Gradia posterior and 368 for Gradia anterior, a property that influences their selection in relation to the particularity of the clinical case (Figure 3, Figure 4).
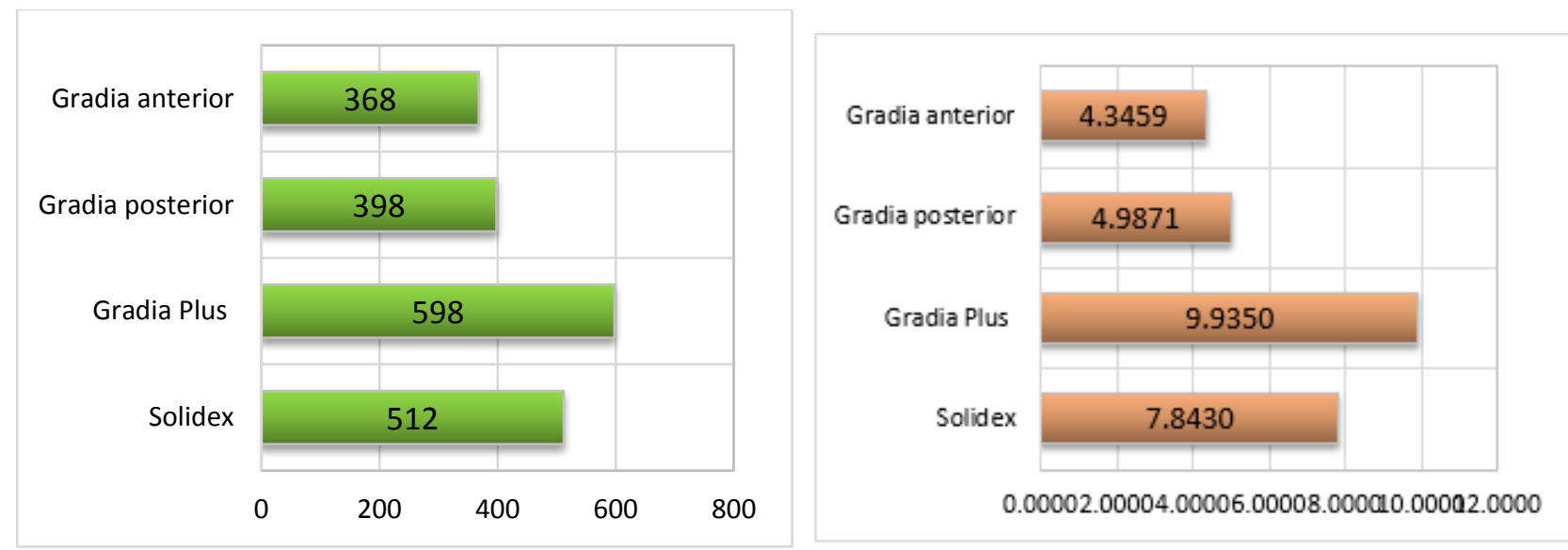

Figure 3, 4. Aspect of hardness and elasticity moduls at biomaterials analysed

In order to try and to give strength and polishability both in -a single composite, manufacturers have introduced resin composite hybrid with smaller particles, the size of the average of the particles at about $0.02 \mu \mathrm{m}$ to $1 \mu \mathrm{m} .9$. This allows the clinician to deploy a single restoring material, with all the properties of mechanical and physical improvement of the prior resins.

The major disadvantage of these types of composites is in need of maintain the gloss. The gloss is satisfactory at first, but tends to be lost over time.

Table 2. Comparison between the clinical problems raised by the composite resins used in the clinic and those used in the laboratory

\begin{tabular}{|c|c|}
\hline CLINICAL & LABORATORY \\
\hline $\begin{array}{c}\text { Contraction during polymerization leads to open contacts. The risk } \\
\text { of porosity leads to gaps in the material. }\end{array}$ & $\begin{array}{c}\text { The laboratory ensures dimensional stability and eliminates any } \\
\text { porosity. }\end{array}$ \\
\hline $\begin{array}{c}\text { The variable rate of wear leads to restrictions on the application in } \\
\text { the posterior area of the oral cavity. }\end{array}$ & $\begin{array}{c}\text { The surfaces have a hardness with a wear rate compatible with that } \\
\text { of the substance of the natural tooth. }\end{array}$ \\
\hline
\end{tabular}




\begin{tabular}{|c|c|}
\hline $\begin{array}{l}\text { The micro-sites created around the edges of the recovery lead to } \\
\text { problems such as soft deposits, secondary caries and adverse pulp } \\
\text { response. }\end{array}$ & Significant reduction of micro-places. \\
\hline Polymerization can cause stress. & Minimal reactions only if bonding is used. \\
\hline $\begin{array}{l}\text { Load particles can generate rough surfaces (not when using } \\
\text { microfilament resins). }\end{array}$ & $\begin{array}{l}\text { The homogeneity of the microphilic structure does not allow to } \\
\text { obtain such an effect. }\end{array}$ \\
\hline Difficulties in creating morphology with the free hand. & $\begin{array}{l}\text { Any required design will be manufactured in the laboratory and } \\
\text { returned ready for fixing. }\end{array}$ \\
\hline $\begin{array}{c}\text { The change in color during polymerization causes difficulties in } \\
\text { choosing the shade. }\end{array}$ & $\begin{array}{l}\text { The laboratory has materials that ensure color stability. Subsequent } \\
\text { modifications can be made if another shade is obtained. They can } \\
\text { be easily re-polished in the oral cavity and can be repaired just as } \\
\text { easily with composite resins used in the clinic. }\end{array}$ \\
\hline
\end{tabular}

Following the methods of using them to initiate the polymerization on laboratory state (high physical factors that intervene), is obtained a material with inherent outstanding.

Compared withthe acrylates these composite resins are much more resistant to wear during a good color stabilization assured by the acrylate. It is also worth noting the high degree of polishing that can be used clinically. These materials can be repolished after their period of alteration and used again with the same glow which is a very important technical detail for clinicians and patient. Another important aspect is the one that most clinicians seem to accept, namely that these glossy surfaces are accepted by the gingival tissues with a minimal inflammatory response. Composite resins have a wear rate very close to that of natural teeth. This aspect of the problem puts them in a favorable light in terms of clinical use. Many researchers made are aimed to calculating the resistance of their composite photo polimerizable in time [31-33]. The study also stopped comparatively on the different types of light - curable composite resins. Thus, a study conducted by David James, following for a period of 3 years a composite resin for laboratory use, was followed by another study carried out by Mitchen on several composite resins for clinical use over a period of more than 5 years. A clinical study conducted by Bishop over a period of over 4 years showed that using laboratory composite resins, 91 clinically satisfactory inlays were obtained from 92 follow-up inlays. The only unsatisfactory inlay was the first one made, which leads to the idea that it could be an error due to lack of experience. Another study, conducted this time by the University of Alabama, reveals its strength in time of the crowns of the shell/coating made of this material. The results demonstrate an average annual wear of $7 \mu \mathrm{m} /$ year. This value approaches the laboratory composite resins abrasion to that of the structure of the natural tooth. It worth remember the fact that the rate of abrasion decreased during the study, that can make us to believe that timefor use of this material in the oral cavity may be extended. Comparison of a number of other materials and laboratory resins makes us realize the clinical importance of them[34-36].

The composite resin is one of the most versatile dental materials and when it is used correctly, with peculiar attention, can provide restorations comparable with the ceramics. The appropriate usage often requires a further training further to get a level of master skill. When used in appropriate situations, these materials have to last many years, the strength and maintenance of gloss being a significant gain. The ability to be minimally invasive and to preserve the structure of the tooth is another significant benefit. Composites are used in a regular manner to restore cavities, closing spaces, lengthening teeth, covering dark teeth or colored and for bonding tooth fractures[37-39].

Selecting the type of material suitable for certain clinical situations, such as mentioned above, it is a matter open to debate. Hybrid and microfilled composites are often used in combination to achieve a restorative result that provides optimal physical and mechanical properties. The hybrid material provides strength and opacity, and the microfill provides the ultimate shine and shine durability. This incremental layering technique with composite resins leads to an optimal polymerization depth, with the reduction of shrinkage effects or stress forces during the polymerization. In addition, the polychromatic effect can be observed when layering different restorative components with various refractory indices, different shades and opacities. By using anatomical layering by successfully overlapping the dentin, enamel and incisal composite, a more realistic color can be obtained, similar to the surface and optical characteristics that mimic nature. 
The use of resins is important when patients present with diastema. The diastema may be due to small congenital teeth, or it may be a situation where there is simply a larger space between the teeth. The use of composite resins in this type of situation is minimally invasive and usually reversible. In general, no dental structure should be removed, and the procedure is done in a single session. When the space is small, the material for this type of clinical situation can be either a microfill composite or a nanocomposite, both of which are easy to handle and provide an excellent final result.When a patient presents with the fracture of the ceramic facets on an extended bridge, the composite resin can be used to repair the defect. This type of procedure is not always predictable, but when performed correctly and with proper occlusion control, a successful outcome can be achieved. When performing a defect repair with metal exposure, many composite materials are required. The use of opaquer, pigments, hybrid substances or nanofillers in the final layer can provide a beautiful result by masking the underlying metal structure. Manufacturers are constantly striving to improve the physical properties and ease of use of these materials. New nanomaterials are welcome supplements to the already refined range of composite resins available for clinical use [40-42].

Laboratory composite resins offer two distinct advantages that can reduce the risk of periodontal reactions. Second, the edge of the work should be extended subgingivally where the dental structure is deficient. Coronary restorations of this type appear to be associated with excellent tolerance on the part of the gingival tissues.

Depending on the qualities of the composite resins produced, each manufacturer gives certain indications that he considers valid.

Taking into account both the multitude of producers and the variety of types of composite resins, it is very difficult to give general indications of this type of biomaterials. However, some of the basic indications of these materials could be: inlays, onlays; shell crowns; bridges; vestibular facets; restorations following endodontic treatments; There are no specific contraindications to this type of material.

\section{Conclusions}

Composite resins offer a conservative and cost - effective solution for many clinical situations.

The use of laboratory composite resins appears as a natural necessity in joint prostheses. This conclusion is based on the increase in the level of aesthetic demand from patients from all walks of life.

Light- curable composite resins are a very good solution in the case of aesthetic restorations, where for various reasons, the use of porcelain is not indicated.

\section{References}

1.JACKSON RD, MORGAN M. The new posterior resins and a simplified placement technique. J Am Dent Assoc. 2000;131(3):375-383.

2.ROBERSON TM, HEYMANN HO, SWIFT EJ Jr. Sturdevant's Art and Science of Operative Dentistry. 4th ed. St Louis, MO: Mosby; 2002.

3.MYSHKO D. NANOTECHNOLOGY: It's a small world. PharmaVOICE. February 2004;34-39.

4.DAVIS N. A nanotechnology composite. Compend Contin Educ Dent. 2003;24(9):662-670.

5.TERRY DA, LEINFELDER KF, GELLER W, et al. Aesthetic \& Restorative Dentistry. Everest Publishing Media; 2009.

6.ABBAS G, FLEMING GJP, HARRINGTON E, SHORTALL ACC, BURKE FJT. Cuspal movement în premolar teeth restored with a packable composite cured în bulk or incrementally. J Dent. 2003;31:437-444.

7.BRAGA RR, FERRACANE JL. Alternatives în polymerization contraction stress management. Crit Rev Oral Biol Med. 2004;15:176-184.

8.DAVIS N. A nanotechnology composite. CompendContinEduc Dent. 2003;24(9):662-670. 
9.FLEMING GJP, HALL D, SHORTALL ACC, BURKE FJT. Cuspal movement and microleakage în premolar teeth restored with posterior filling materials of varying reported volumetric shrinkage values. J Dent. 2005;33(2):139-146.

10.FLEMING GJP, KHAN S, AFZAL O, PALIN WM,. BURKE FJT. Investigation of polymerisation shrinkage strain, associated cuspal movement and microleakage of MOD cavities restored incrementally with resin-based composite using an LED light curing unit. J Dent. 2007; 35:97-103.

11.MUCCI V, ARENAS G, DUCHOWICZ R, COOK WD, VALLO C. Influence of thermal expansion on shrinkage during photopolymerization of dental resins based on bis-GMA/TEGDMA. Dent Mater. 2009;25:103-114.

12.MYSHKO D. Nanotechnology: It's a small world. PharmaVOICE. February 2004;34-39.

13.NICOLA C, CARA RR, SAVA S, ROMÎNU M, FLORIȚA Z, BONDOR CI. Relevance of adhesive systems evolution on microleakage of composite restorations. J Dent Res 86(Spec Iss B, IADR/CEDID): 0216, 2007

14.TERRY DA, LEINFELDER KF, GELLER W, et al. Aesthetic \& Restorative Dentistry. Everest Publishing Media; 2009.

15.VAN MEERBEEK B, DE MUNCK J, YOSHIDA Y, INOUE S, VARGAS M, VIJAY P, VAN LANDUYT K, LAMBRECHTS P, VANHERLE G. Buonocore memorial lecture: adhesion to enamel and dentin: current status and future challenges. Oper Dent. 2003;28:215-235.

16.FERRACANE JACK L. Resin composite - State of the art, Dental Materials 2011;27:29-38.

17.***Craig`s. Restorative Dental Materials. 13th Edition. Philadelphia: Elsevier Mosby; 2012. p. 175182.

18.McCABE JF, WALLS AWG. Applied dental materials. 9th ed. Oxford:Blackwell Publishing Ltd; 2oo8. p. 196-216.

19.WEINMANN W, THALACKER C, GUGGENBERGER R. Siloranes in dental composites. Dental Materials 2005;21:68-74.

20.ROMÂNU M, BRATU D. Materiale Dentare: Noţiuni teoretice şi aplicaţii clinice. Timişoara (RO): Ed. Brumar; 2003. p. 187-207.

21.BEHR M, ROSENTRITT M, FALTERMEIER A, HANDEL G. Electron beam irradiation of dental composites. Dent Mater 2005;21:804-10.

22.KIM SH, WATTS DC. Effect of glass-fiber reinforcement and water storage on fracture toughness (KIC) of polymerbased provisional crown and FPD materials. Int J Prosthodont 2004;17:318-322.

23.SUBIR D, WUNDERA SL, MCCOOLB JI, BARANC GR. Silane treatment effects on glass/resin interfacial shear strengths. Dental Materials 2003; 19: 441-448.

24.MERIC G, DAHL JE, RUYTER IE. Physicochemical evaluation of silica-glass fiber reinforced polymers for prosthodontic applications. Eur J Oral Sci 2005; 113: 258-264.

25.FERRACANE JL. Hygroscopic and hydrolytic effects in dental polymer networks. Dent Mater 2006;22:211-222.

26.DYER SR, LASSILA LV, JOKINEN M, VALLITTU PK. Effect of fiber position and orientation on fracture load of fiberreinforced composite. Dent Mater 2004;20:947-955.

27.Van HEUMENA CCM, KREULENA CM, BRONKHORST EM, LESAFFREC E, CREUGERSA NHJ. Review: Fiber-reinforced dental composites in beam testing. Dental Materials 2008; 24:14351443.

28.WOO ST, YU B, AHN JS, LEE YK. Comparison of translucency between indirect and direct resin composites. Journal of Dentistry 2008;36:637-642.

29.PARAVINA RD, WESTLAND S, JOHNSTON WM AND POWERS JM. Color Adjustment Potential of Resin Composites. J Dent Res 2008;87(5):499-503.

30.IKEDA T, SIDHU SK, OMATA Y, FUJITA M, SANO H. Color and translucency of opaque-shades and body-shades of resin composites. European Journal of Oral Science 2005;113:170-3.

31.HILL EE, LOTT, J., A clinically focused discussion of luting materials. Australian Dental Journal 2011;56:(1 Suppl): 67-76. 
32.HIKITA K, VAN MEERBEEK B, DE MUNCK J et al. Bonding effectiveness of adhesive luting agents to enamel and dentin. Dent Mater 2007;23(1):71-80.

33.MANGANI F., CERRUTI A., PUTIGNANON A ., BOLLERO L, MADINI L. Clinical approach to anterior adhesive restorations using resin composite veneers. The European Journal of esthetic dentistry 2007;2(2):28-50.

34.DE MUNCK et al. A Critical review of the durability of adhesion to tooth tissue: methods and results. J Dent Res 2005;84(2):118-132.

35.VAN MEERBEEK B et al. Adhesion to enamel and dentin: current status and future challenges. Operative Dentistry 2003;28(3):215-235.

36.NICOLA C, SAVA S, DUDEA D, BONDOR CI, ŞOANCĂ A, COLCERIU L, et al. Influence of adhesive systems composition on dual-cured resin cements. Journal of Optoelectronics and Biomedical Materials 2009;1(4): $331-337$.

37.BEHR M, ROSENTRITT M, SIKORA MI, KARL P, HANDEL G. Marginal adaptation and fracture resistance of adhesively luted glass fibre-composite reinforced molar crowns with different inner crown surfaces. J Dent 2003;31:503-508.

38.***ADA Council on Scientific Affairs. Direct and indirect restorative materials. J Am Dent Assoc 2003;134:463-472.

39.RYGE G. Clinical criteria. Int Dent J 1980;30:347-358. 34. Raj V, Macedo G, Ritter A, Swift E. Longevity of posterior composite restorations. J Esthet Restor Dent 2007;19:3- 5.

40.RAMMELSBERG P, SPIEGL K, EICKEMEYER G. Clinical performance of metal-free polymer crowns after 3 years in service. J Dent 2005;33(5):517-23.

41.OHLMANN B., DREYHAUPT J., SCHMITTER M., GABBERT O. Clinical performance of posterior metal-free polymer crowns with and without fiber reinforcement. One-year results of a randomized clinical trial. J Dent 2006;34(10):757-82

42.OHLMANN B, GRUBER R, EICKEMEYER G, RAMMELSBERG P. Optimizing preparation design for metal-free composite resin crowns. J Prosthet Dent 2008; 100 (3): 211-9.

Manuscript received: 16.06 .2020 